\title{
Automatic Electronic Device Used for the Evaluation of Cyclic-Fatigue Resistance of Nickel-Titanium Instruments
}

\section{Dispositivo electrónico automático usado para la evaluación de la resistencia a la fatiga cíclica de instrumentos de Niquel-Titanio}

Cesar Gaitán-Fonseca DDS, MSc, PhD1; Edith Lara-Alvarado DDS, MSc²; Héctor Flores-Reyes DDS, MSc, PhD³; Amaury Pozos-Guillén DDS, MSc, PhD; Verónica Méndez-González DDS, MSc ${ }^{4}$

1. Profesor-Investigador. Maestría en Ciencias Biomédicas, Área de Ciencias de la Salud, Universidad Autónoma de Zacatecas, México.

2. Colaboradora Académica. Facultad de Estomatología, Universidad Autónoma de San Luis Potosí, México.

3. Profesor-Investigador. Laboratorio de Ciencias Básicas, Facultad de Estomatología, Universidad Autónoma de San Luis Potosí, México.

4. Profesora-Investigadora. Maestría en Endodoncia, Facultad de Estomatología, Universidad Autónoma de San Luis Potosí, México.

Correspondence to: Dr. Amaury de Jesús Pozos Guillén - apozos@uaslp.mx

Received: 20-XI-2016

Accepted: 30-XI-2016

Published Online First: 6-XII-2016

DOI: http://dx.doi.org/10.15517/ijds.v0i0.27288

\section{ABSTRACT}

The aim of this study was to evaluate the cyclic-fatigue fracture of different Nickel-Titanium motor-driven rotary instruments (ProTaper $\AA$ Universal, ProFile $\AA$, and Mtwo $®$ systems) in artificial canals by means of an Automatic Electronic Device (AED). The study was performed using NickelTitanium instruments 25/0.06 evaluated in canals with a 45-degree curvature and 2-mm radius. The analyses evaluated two parameters: fracture by cyclic fatigue, and time of fracture; in addition, the length of separated fragment was evaluated. Medians and range values were calculated for each group. Data were analyzed by the Kruskall-Wallis and Mann-Whitney U tests to determine statistical difference. The ProFile motor-driven rotator system exhibited highest resistance to fracture due to cyclic fatigue and highest fracture time compared with the ProTaper and Mtwo systems $(p<0.05)$. The equipment proposed in this study (AED) demonstrated efficiency for recording information, automation, scheduled work times and durations, cycle number, time of fracture, pressure changes and, principally control of the human factor.

\section{KEYWORDS}

Cyclic-fatigue; Nickel-Titanium instruments; Automatic electronic device; Rotary instruments; ProTaper ${ }^{\circledR}$ Universal System; ProFile ${ }^{\circledR}$ System; Mtwo ${ }^{\circledR}$ System. 


\section{RESUMEN}

El objetivo del presente estudio fue evaluar la fractura a la fatiga cíclica de diferentes instrumentos rotatorios de Niquel-Titanio (sistemas ProTaper $®$ Universal, ProFile $®$ y Mtwo $®$ ) en conductos artificiales por medio de un Dispositivo Electrónico Automático (DEA). Se usaron instrumentos de Niquel-Titanio 25/0.06, los cuales se evaluaron en conductos con una curvatura de 45 grados y 2 milímetros de radio. Se analizaron dos parámetros: Fractura a la fatiga cíclica y tiempo a la fractura; además se evaluó la longitud del fragmento separado. Medianas y rangos fueron calculados para cada uno de los grupos. Los resultados fueron analizados por las pruebas de Kruskall-Wallis y $\mathrm{U}$ de Mann-Whitney para determinar diferencias estadísticas. El Sistema ProFile mostró una mayor resistencia y tiempo a la fractura en comparación con los sistemas ProTaper y Mtwo $(p<0.05)$. El equipo propuesto en este estudio (DEA) demostró eficiencia para el registro de la información, tiempos de trabajo y duración, número de ciclos, tiempo a la fractura, cambios en la presión y principalmente control del factor humano.

\section{PALABRAS CLAVE}

Fatiga cíclica; Instrumentos Niquel-Titanio; Dispositivo electrónico automático; Instrumentos rotatorios; Sistema ProTaper $®$ Universal; Sistema ProFile $® ;$ Sistema Mtwo®.

\section{INTRODUCTION}

Several rotary and reciprocating NickelTitanium (NiTi) systems are available for dental instrumentation under different conditions as follows: curved; straight, and c-shaped canals (1). The physical characteristics (elasticity and flexibility) of these systems are based on decreased operative times and patient safety. The main advantage is enhancement of canal shaping and reduced transportation in curved and c-shaped canals through endodontic treatment $(2,3)$.

During curved-canal instrumentation, rotary systems exhibit stress and torsion with the possibility of distortion and fracture (4-6). Fracture of the motor-driven rotary instrument is produced in two ways: cyclic fatigue, and torsional fatigue. Cyclic-fatigue fracture occurs when the instruments rotate freely in a curvature, generating tension/compression cycles in the region of maximal flexure until fracture $(7,8)$. The incidence of fracture by cyclic fatigue in handheld instruments is 1-6\% as compared with that of rotary instruments, which is 0.4-5\% (9-11). To evaluate cyclic fatigue in rotary instruments, different devices have been employed (5, 12-14). Automatic Electronic Device (AED) is proposed as a new biomedical technology to measure endodontic clinical values under experimental conditions.

Material fatigue describe the variations in properties due to an application of cyclic loads, which is usually associated with tension/compression or a bending/rotation fatigue rupture (15). In endodontic treatment, cyclic-fatigue fracture occurs when the instrument rotates in a root canal, generating tension/compression cycles (16).

The aim of this study was to evaluate the cyclic-fatigue resistance of different NiTi instruments

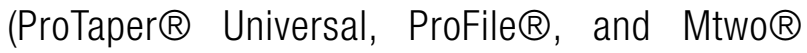
systems) in artificial canals utilizing an AED.

\section{METHODS}

Manufacture of AED. AED was designed to simulate the conditions of $\mathrm{NiTi}$ rotatory systems mounted in a dental piece. With AED, it is possible to control force and velocity under experimental conditions and to obtain estimated values concerning the work conditions of $\mathrm{NiTi}$ 
rotatory instruments. AED is constituted of four components: a) main support; b) control box; c) calibration sensor, and d) Experimental Endodontic Block (EEB) (Figure 1). Its operation comprised an 8-bit, 16-MHz crystal PIC16F874 microcontroller. The support possessed vertical movement and horizontal rotation for the Endodontic Electric Motor (EEM) in order to operate a NiTi rotary instrument and to simulate the clinical conditions in the dental piece. The control box allows the introduction and recording of data for experimental analysis. This control box permits the following operating program: 1) calibration of AED; 2) providing the initial and final position; 3) transportable schedule instrument in EEB; 4) work time; 5) data recording, and 6) log-in. Finally, the AED recorded cycle number, work time, applied force, weight detection, and elapsed time. The calibration sensor was programmed at $1.03 \mathrm{~N}$ (17). The EEB was manufactured with artificial canals of different curvatures with 2-mm radii, $1.5 \mathrm{~mm}$ in depth, and $1.5 \mathrm{~mm}$ in diameter. The curvature angle employed was 45 degrees. Parameters of the curvature employed in the present study were designed according to the Schneider and Prudent method (18).

Rotary systems. The rotary instruments were divided into three experimental groups: the 25/0.08 ProTaper Universal group (DENTSPLY, Ballaigues, Switzerland); the 25/0.06 ProFile group (DENTSPLY Maillefer, USA), and the 25/0.06 Mtwo group (VDW, Frankfurt, Germany), with 10 samples per group.

Protocol for fracture by cyclic fatigue. In AED, an X-SmartTM (EEM) 16:1 reduction (DENTSPLY, Ballaigues, Switzerland) was adapted. Instruments were mounted onto EEM and positioned at the same point. Working duration was established at $19 \mathrm{~mm}$ and a constant speed of 300 revolutions per min (rpm) was utilized. For recording cycle number and fracture time, a 1:100-sec stopwatch was used. For measurement of the separated fragment, a standardized endodontic millimetric ruler (Hu-Friedy, USA) was employed. Additionally, instruments were analyzed by Scanning Electronic Microscopy (SEM). Data were analyzed by KruskalWallis and Mann-Whitney $U$ tests; statistical significance was set at $p<0.05$.

\section{RESULTS}

Results of fracture for each group showed that the ProFile group exhibited highest resistance to cyclic- fatigue fracture compared with the ProTaper and Mtwo groups $(p<0.05)$. Results for fracture time and the difference between the Mtwo and the ProTaper systems were statistically significant $(p<0.05)$, demonstrating that the ProFile group exhibited a statistically significant difference in terms of fracture time when compared with the ProTaper and Mtwo groups $(p<0.05)$; additionally, the difference between the Mtwo and ProTaper groups was statistically significant $(p<0.05)$ (Figure 2). Mean distanceto-fracture was $4.6 \mathrm{~mm}$. No statistically significant difference in the length of the separated fragments was found among the three instruments $(p>0.05)$. Figure 3 depicts images analyzed by SEM for the experimental groups. Figure 3 a corresponds to the ProTaper Universal fracture by cyclic fatigue with triangular section. Figure $3 \mathrm{~b}$ illustrates the ProFile system with triangular design after fracture, while Figure $3 \mathrm{c}$ presents the Mtwo square transversal design. 


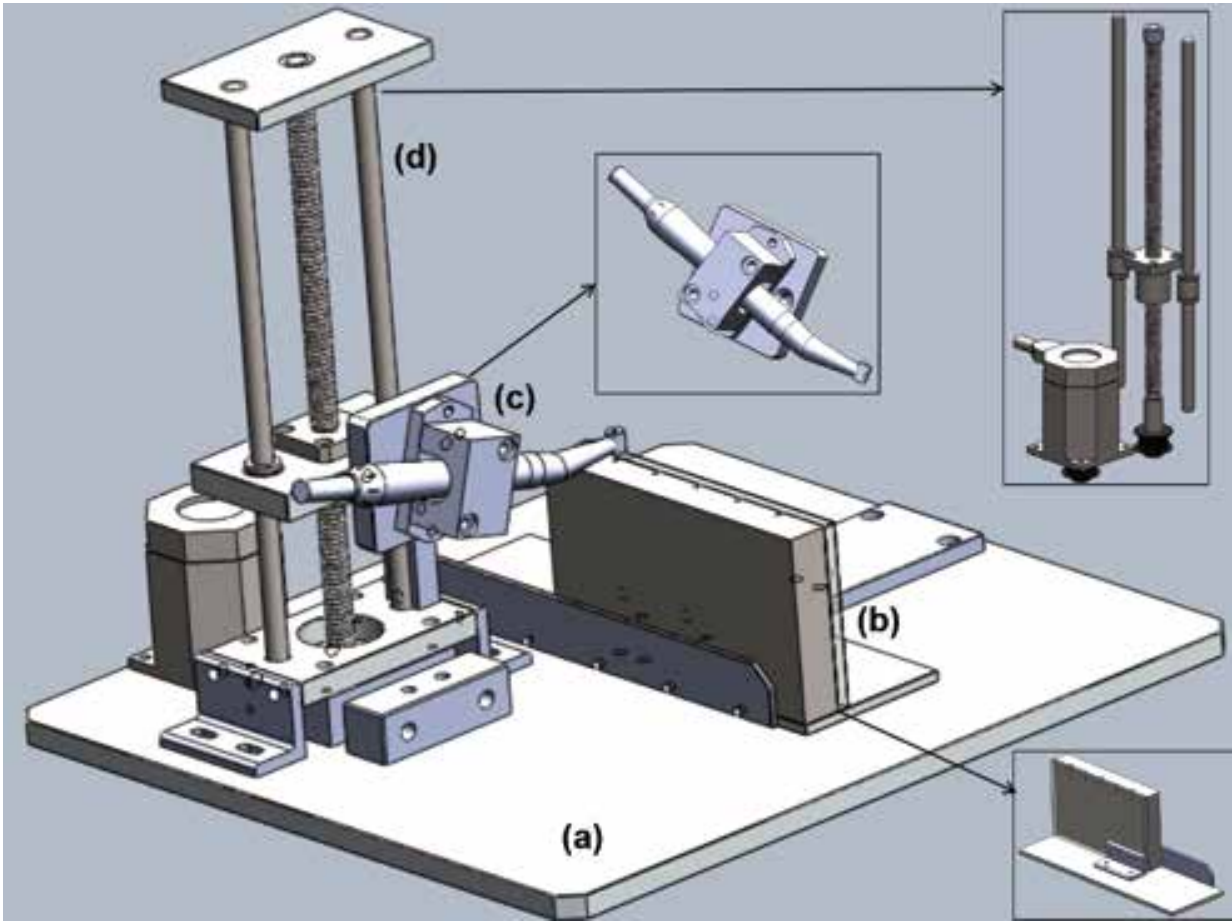

Figure 1. The Automatic Electronic Device (AED) testing device. Schematic diagram of AED: (a) calibration weight as the basis for all samples before the test; (b) Platina and artificial canals for evaluation of cyclic fatigue of the motor-driven rotary systems, with (c) endodontic motor, and (d) main support that regulates cycle movement (up-down).
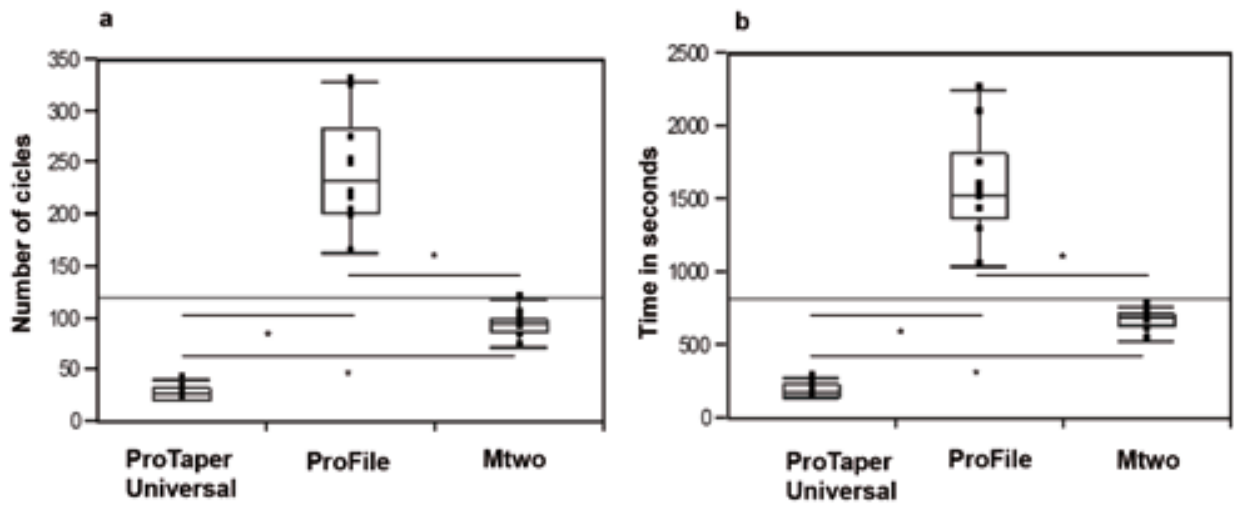

Figure 2. Fracture by cyclic fatigue. The results showed that the Profile $®$ system presents more resistance to cyclic fatigue compared with the ProTaper $\AA$ Universal and Mtwo $\circledR$ motor-driven rotary systems. 

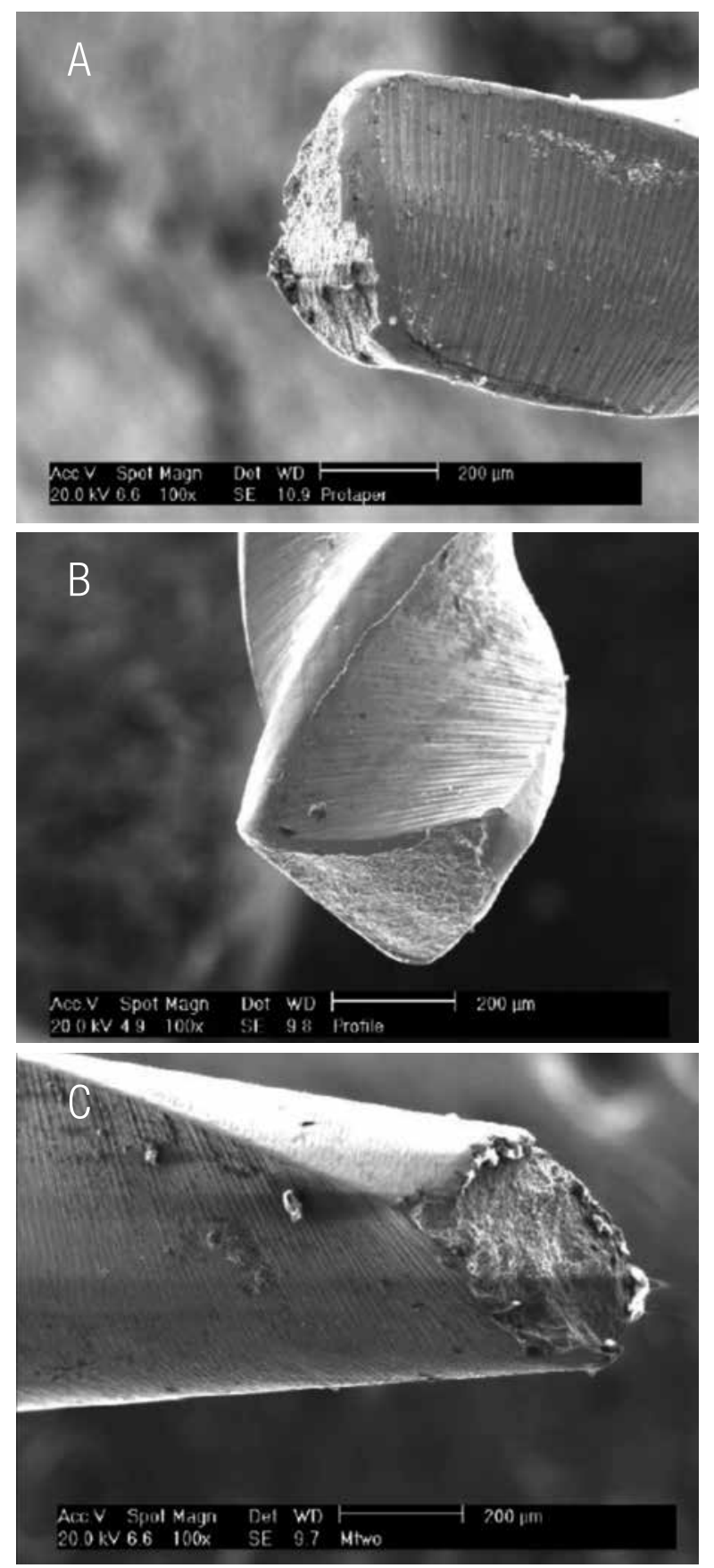

Figure 3. Scanning Electronic Microscopy (SEM) images. All instruments were analyzed under Scanning Electronic Microscopy (SEM) after fracture by cyclic fatigue. In Image 3a, the ProTaper ${ }^{\circledR}$ motor-driven rotary system exhibited a transversal section with fatigue in the metal. In Image 3b, the ProFile ${ }^{\circledR}$ system exhibited deformation in the radial land guide. In Image 3c, the Mtwo $®$ system displayed a transversal section with fracture lines. 
DISCUSSION

Rotary instruments manufactured with NiTi employed in root canal treatment favors working performance in a curved root canal. NiTi flexibility permits $8-10 \%$ plastic deformation in cases of tension (19). When flexibility is excessive, fracture in the rotary instrument presents (7). In root canal instrumentation and rotary-instrument function in curve canals, the compression effect is present and, outside of the curvature, the instrument possesses tensional effort. With these effects, the instrument undergoes tension and compression cycles. These continuous cycles can generate microfractures in the metal nucleus, this phenomenon denominated cyclic fatigue (20).

Gambarini et al (21) evaluated cyclic fatigue in the ProFile system using low and high torque in EEM, exhibiting more resistance to fracture by cyclic fatigue in the low torque compared with the endodontic handpiece. Haikel et al (22) reported that the ProFile system possesses better conditions for evaluating fracture resistance due to its design with a minimal metallic nucleus, compared with $\mathrm{HERO} \otimes$ and Quantec $®$ systems. A previous report showed that the design of the ProFile system proved to be an important factor in fatigue resistance (23). The Mtwo-system design is characterized by control and cutting efficacy, this facilitating instrumentation in curved root canals; this instrument exhibits minimal radial contact compared with $\mathrm{K} 3 \AA$ and $\mathrm{RaCe} \otimes$ systems. Schäfer et al (24) reported that apical transportation does not exist.

The present study evaluated fracture by means of the cyclic fatigue of different NiTi rotary systems. The ProFile group resisted more cycles when compared with the ProTaper Universal and Mtwo systems. Previous reports (including those in which fracture time was evaluated) demonstrated that the ProFile system lasts more time prior to the presence of the fracture in comparison with
Mtwo, HERO Shaper $\circledast$, K3, Alpha $®$, and ProTaper systems (22-26). On the other hand, there are a few reports regarding the separated segment of the instruments (27). The "gold standard" for evaluating NiTi rotary systems is the natural curved root canal, but the problem comprises one-time use, which is not reproducible for experimental designs (26); thus, AED and EEB with artificial canals have been manufactured for this purpose. Pruett and Schneider (15) proposed a method for standardizing artificial curvatures in experimental designs. Uei-Ming Li et al (5) worked with an inclined-plane device. In this device, the instrument rotates in an endodontic motor and functions in different curvatures. The endodontic motor was subjected to the Instron testing device. The disadvantage lies in maintaining constant pressure and finding the precise angle.

Instead, Gambarini et al (28) evaluated cyclic fatigue in a metal block with a 60-degree curvature; the EEM was mounted on a mobile device. Soo-Youn et al (24) manufactured a fatiguetesting device (Denbotix; Bucheon, Korea) with the capacity for movement and velocity control. This device possesses an internal sensor that detects changes in the motor and in the torque. Denbotix is the device with the most effective parameters for carrying out adequate evaluation of cyclic fatigue as reported in the literature. The handmade device elaborated for the present study utilized artificial canals in an EEB with 45-degree angles; this device permitted control of rpm, angle curvature, force applied, and torque control.

The main advantages of AED proposed here compared with other devices include the capability for recording information, automation, scheduled work times and durations, cycle number, time of fracture, pressure changes and, mainly, control of the human factor (29). The AED is proposed for the management of experimental studies in rootcanal instruments employed with a coupled EEM. This device demonstrated efficiency in evaluating 
parameters for cyclic fracture, allowing the control of applied force, velocity, and torquing.

\section{CONCLUSIONS}

The ProFile motor-driven rotator system showed highest resistance to fracture due to cyclic fatigue and highest fracture time compared with the ProTaper and Mtwo systems, utilizing a new, handmade AED.

\section{CONFLICT OF INTERESTS}

The authors indicated no potential competing interests relationship with any manufacturer of the commercial equipment and instruments featured in this manuscript.

\section{ACKNOWLEDGMENTS}

The English-language reviewing of the manuscript by Maggie Brunner has been particularly appreciated.

\section{REFERENCES}

1. Hiran-Us S., Pimkhaokham S., Sawasdichai J., Ebihara A., Suda H. Shaping ability of ProTaper NEXT, ProTaper Universal and iRace files in simulated S-shaped canals. Aust Endod J. 2016; 42 (1): 32-6.

2. Gambarini G., Gergi R., Grande N. M., Osta N., Plotino G., Testarelli L. Cyclic fatigue resistance of newly manufactured rotary nickel titanium instruments used in different rotational directions. Aust Endod J. 2013; 39 (3): 151-4.

3. Lee W., Hwang Y. J., You S. Y., Kim H. C. Effect of reciprocation usage of nickeltitanium rotary files on the cyclic fatigue resistance. Aust Endod J. 2013; 39 (3):146-50.

4. Topçuoğlu H. S., Pala K., Aktı A., Düzgün S., Topçuoğlu G. Cyclic fatigue resistance of D-RaCe, ProTaper, and Mtwo nickel-titanium retreatment instruments after immersion in sodium hypochlorite. Clin Oral Investig. 2016; 20 (6): 1175-9.

5. Li U. M., Lee B. S., Shih C. T., Lan W. H., Lin C. P. Cyclic fatigue on endodontic nickel titanium rotary instruments: static and dynamic tests. J. Endod. 2002; 28 (6): 448-51.

6. Chaves Craveiro de Melo M., Guiomar de Azevedo Bahia M., Lopes Buono V. T. Fatigue resistance of engine-driven rotary nickel-titanium endodontic instruments. J. Endod. 2002; 28 (11): 765-9.

7. Capar I. S., Ertas H., Arslan H. Comparision of cycle fatigue resistance of novel nickeltitanium rotary instruments. Aust Endod J. 2015; 41 (1): 24-8.

8. Arslan H., Alsancak M., Doğanay E., Karataş E., Çapar I. D., Ertas H. Cyclic fatigue analisis of Reciproc R25® instruments with different kinematics. Aust Endod J. 2016; 42 (1): 22-4.

9. Crump M. C., Natkin E. Relationship of broken root canal instruments to endodontic case prognosis: a clinical investigation. J. Am Dent Assoc. 1970; 80 (6): 1341-7.

10. Pettiette M. T., Conner D., Trope M. Procedural errors with the use of nickeltitanium rotary instruments in undergraduate endodontics. J. Endod. 2002; 28 (3): 259.

11. Al-Fouzan K. S. Incidence of rotary ProFile instrument fracture and potential for by passing in vivo. Int Endod J. 2003; 36 (12): 864 -7.

12. Yared G. M., Bou Dagher F. E., Machtou P. Cyclic fatigue of ProFile rotary instruments after clinical use. Int Endod J. 2000; 33 (3): 204-7.

13. Grande N. M., Plotino G., Pecci R, Bedini R., V. A. Malagnino, F. Somma. Cyclic fatigue resistance and threedimensional analysis of instruments from two nickel- titanium rotary systems. Int Endod J. 2006; 39 (10): 755-63.

14. Cheung G. S., Darvell B. W. Fatigue testing of a NiTi rotary instrument. Part 1: strain-life relationship. Int Endod J. 2007; 40 (8): 612-8.

15. Eggeler G., Hornbogen E., Yawny A., Heckmann A., Wagner M. Structural and 
functional fatigue of NiTi shape memory alloys. Mater Sci Eng A. 2004; 378 (1-2): 24-33.

16. Sattapan B., Nervo G. J., Palamara J. E., Messer H. H. Defects in rotary nickeltitanium files after clinical use. J. Endod. 2000; 26 (3): 161-5.

17. Gabathules H., Hassell T. A pressure sensitive periodontal probe. Helv Odontol Acta. 1971; 15 (2): 114-7.

18. Schneider San W. A comparison of canal preparations in straight and curved root canals. Oral Surg Oral Med Oral Pathol 1971; 32 (2): 271-5.

19. Thompson S. A. An overview of nickeltitanium alloys used in dentistry. Int Endod J. 2000; 33 (4): 297-310.

20. Young G. R., Parashos P., Messer H. H. The principles of techniques for cleaning root canals. Aust Endod J. 2007; 52 (1 Suppl): S52-63.

21. Gambarini G. Cyclic fatigue of nickeltitanium rotary instruments after clinical use with low- and high-torque endodontic motors. J. Endod. 2001; 27 (12): 772-4.

22. Haikel Y., Serfaty R., Bateman G., Singer B., Allemann C. Dynamic and cyclic fatigue of engine driven rotary nickel-titanium endodontic instruments. J. Endod. 1999; 25 (6): 434-40.

23. Tripi T. R., Bonaccorso A., Condorelli G. G. Cyclic fatigue of different nickel-titanium endodontic rotary instruments. Oral Surg Oral Med Oral Pathol Oral Radiol Endod. 2006; 102 (4): e106-14.
24. Schäfer E., Erler M., Dammaschke T. Comparative study on the shaping ability and cleaning efficiency of rotary Mtwo instruments. Part 1. Shaping ability in simulated curved canals. Int Endod J. 2006; 39 (3): 196-202.

25. Soo-Youn H., So-Ram O., Yoon L., SangMin L., Kee-Yeon K. Effect of cross-sectional area of 6 nickel-titanium rotary instruments on the fatigue fracture under cyclic flexural stress: A fractographic analysis. J. Korean Acad Conserv Dent. 2009; 34 (5): 424-9.

26. Plotino G., Grande N. M., Cordaro M., Testarelli M., Gambarini G. A Review of cyclic fatigue testing of nickel-titanium rotary instruments. J. Endod. 2009; 35 (11): 401-3.

27. Testarelli L., Grande N. M., Plotino G., Lendini M., Pongione G., De Paolis G., et al. Cyclic fatigue of different nickel-titanium rotary instruments: A comparative study. Open Dent J. 2009; 3: 55-8.

28. Gambarin G., Grande N. M., Plotino G., Somma F., Garala M. Fatigue resistance of engine-driven rotary nickel-titanium instruments produced by new manufacturing methods. J. Endod. 2008; 34 (8): 1003-5.

29. Pedullà E., Lo Savio F., Boninelli S., Plotino G., Grande N. M., La Rosa G., Rapisarda E. Torsional and cyclic fatigue resistance of a new nickel-titanium instrument manufactured by electrical discharge machining. J. Endod. 2016; 42, (1): 156-9. 